\title{
Investigation of Electroless Cobalt-Phosphorous Layer and Its Diffusion Barrier Properties of Pb-Sn Solder
}

\author{
MUH-WANG LIANG, ${ }^{1,2}$ HUI-TING YEN, ${ }^{1}$ and TSUNG-EONG HSIEH ${ }^{1}$ \\ 1.-Department of Materials Science and Engineering, National Chiao Tung University, Hsinchu, \\ Taiwan 30010, R.O.C. 2.—E-mail: MWLiang@itri.org.tw
}

The capability of a cobalt-phosphorous $[\mathrm{Co}(\mathrm{P})]$ layer, which was grown via the electroless plating process, to serve as the diffusion barrier of lead-tin ( $\mathrm{PbSn})$ solder was investigated in this work. The Auger electron spectroscopy (AES) and energy dispersive spectrometry (EDX) indicated that the phosphorous contents in $\mathrm{Co}(\mathrm{P})$ films decrease with increasing film thickness and that the average contents are no less than 8.7 at.\% for the specimens prepared in this work. X-ray diffraction in conjunction with composition analyses revealed that the electroless $\mathrm{Co}(\mathrm{P})$ layer was a mixture of amorphous and nanocrystalline structures; however, the AES depth profile and subsequent analyses indicated that the first-formed $\mathrm{Co}(\mathrm{P})$ layer should be amorphous because it contains as much as 18 at.\% P. This implied a good barrier capability for electroless $\mathrm{Co}(\mathrm{P})$ because, as revealed by EDX line scan, the $\mathrm{Sn}$ and $\mathrm{Cu}$ atoms could not penetrate the $\mathrm{Co}(\mathrm{P})$ layer after the $\mathrm{PbSn} / \mathrm{Cu} / \mathrm{Co}(\mathrm{P}) / \mathrm{Cu} / \mathrm{Ti} / \mathrm{Si}$ sample was subjected to annealing at $250^{\circ} \mathrm{C}$ in a forming gas ambient for $24 \mathrm{~h}$. The fact that $\mathrm{Sn}$ and $\mathrm{Cu}$ underlayers could not penetrate the Co layer after such a liquid-state annealing step was evidence that the $\operatorname{Co}(\mathrm{P})$ layer may simultaneously serve as a diffusion-barrier interlayer dielectric and as an under-bump metallization for flip-chip copper $(\mathrm{Cu})$ ICs.

Key words: Electroless plating, cobalt-phosphorous, diffusion barrier

\section{INTRODUCTION}

Under bump metallization (UBM) provides good adhesion between the bonding pads and the bumps and serves as a diffusion barrier, a wetting layer, and a protective layer for flip-chip bonding. There are mainly four types of diffusion barrier layer: sacrificial barriers, stuffed barriers, passive compound barriers, and amorphous barriers. ${ }^{1}$ The most common materials used in UBM as diffusion-barrier layers are refractory metals, such as titanium (Ti), tungsten (W), molybdenum (Mo), and alloys thereof. All of these metals have superior diffusion-barrier capability at high temperatures and are in general deposited by physical vapor deposition (PVD). However, when PVD is used as in the recently described deep-submicron $\mathrm{Cu}$-IC processes, the PVD suffers from poor step coverage. ${ }^{2}$ Much effort has been expended to solve this difficulty, and one idea that has surfaced is that of the diffusion-barrier layer in the $\mathrm{Cu}$-IC process being formed by an electroless plating method; $;$,3 presently, the electroless plated nickel (Ni) is most commonly adopted for UBM. ${ }^{4-7}$

(Received October 28, 2005; accepted February 13, 2006)
Nickel has relatively low diffusion and reaction rates with solder, and a Ni layer $5 \mu \mathrm{m}$ thick provides suitable reliability for UBM applications. Further, the low stress status of electroless $\mathrm{Ni}$ is more advantageous than that of $\mathrm{Ni}$ prepared by sputtering. ${ }^{8}$ Because the plating baths for electroless $\mathrm{Ni}$ in general contain sodium hypophosphite $\left(\mathrm{NaH}_{2} \mathrm{PO}_{2}\right)$ as the reducing agent, phosphorus $(\mathrm{P})$ atoms are deposited simultaneously so that electroless $\mathrm{Ni}$ is in fact a nickel-phosphorous alloy $[\mathrm{Ni}(\mathrm{P})]$. It is known that the phosphorous content in $\mathrm{Ni}(\mathrm{P})$ can be adjusted by the $\mathrm{pH}$ value of the plating bath and that the crystalline structure of $\mathrm{Ni}(\mathrm{P})$ changes with phosphorous content. ${ }^{7,9}$ The mixture of microcrystalline and amorphous grains constitutes the $\mathrm{Ni}(\mathrm{P})$ when phosphorous content is in the range of 7-10 wt.\%; when phosphorous content exceeds 10 wt.\%, the Ni(P) layer becomes amorphous. The amorphous electroless $\mathrm{Ni}(\mathrm{P})$ possesses good barrier properties due to the nonexistence of fast diffusion paths, such as grain boundaries.

Electroless cobalt-phosphorous alloys [Co(P)] serving as diffusion barriers of $\mathrm{Cu}$ and polyimide dielectrics in multilayer microelectronic structures 
have been studied by O'Sullivan et al. ${ }^{10}$ Their investigation showed that electroless $\mathrm{Co}(\mathrm{P})$ is highly effective in inhibiting $\mathrm{Cu}$ diffusion at elevated temperatures, even at $\mathrm{Co}(\mathrm{P})$ thickness as low as $50 \mathrm{~nm}$. The electroless $\mathrm{Co}(\mathrm{P})$ also exhibited a better diffusion-barrier effectiveness in comparison with $\mathrm{Ni}(\mathrm{P})$ and pure metals $(\mathrm{Co}, \mathrm{Ni})$. Study of electroless $\mathrm{Co}(\mathrm{P})$ further indicated that phosphorous co-deposition behaviors and its effects on the crystalline structure of $\mathrm{Co}(\mathrm{P})$ are similar to those of electroless $\mathrm{Ni}(\mathrm{P})$. Binary phase diagrams revealed relativity low solubility of $\mathrm{Sn}$ or $\mathrm{Pb}$ in $\mathrm{Co} ;{ }^{11}$ it can thus be speculated that electroless $\mathrm{Co}(\mathrm{P})$ should possesses good barrier capabilities for UBM applications.

Studies have been made investigating the use of electroplated or PVD Co in UBM for the solder bump. ${ }^{12,13}$ Because the Co layers prepared by these methods are polycrystalline, either $\mathrm{W}$ or $\mathrm{P}$ elements were doped into the Co layer to clog up the grain boundaries, thereby improving their ability to retard diffusion. For instance, the $\mathrm{Co}_{0.9} \mathrm{~W}_{0.02} \mathrm{P}_{0.08}$ alloy exhibited better barrier properties in comparison with $\mathrm{Co}_{0.9} \mathrm{P}_{0.1}$ and was capable of withstanding annealing at $450^{\circ} \mathrm{C} .{ }^{14,15}$ However, electroplating is not suitable for ceramic or organic substrates in the UBM process. PVD methods, such as sputtering, are costly. Electroless plating is a selective chemical deposition method; it can reduce the bumping cost significantly because it does not require masking or metal sputtering. ${ }^{6}$ This technique easily allows parallel processing of multiple wafers so that it can offer high throughput. As the capability of electroless $\mathrm{Co}(\mathrm{P})$ as a barrier layer in UBM structure remains to be explored, we carried out this study in order to investigate its feasibility to serve both as the barrier layer in interlayer dielectrics and in UBM for flip-chip Cu-ICs.

\section{EXPERIMENTAL PROCEDURES}

\section{Specimen Preparation}

After the simulated $\mathrm{Ti} / \mathrm{Cu}$ circuit layer on the $\mathrm{Si}$ substrate had been formed by e-beam evaporation and then processed by roughening/sensitization/ activation, the specimens were subjected to electroless plating of different periods of times for depositing $\mathrm{Co}(\mathrm{P})$ layer. Table I lists the methods and solutions for roughening, sensitization, and activation. After the catalytic layer was formed on the specimens, a $\operatorname{Co}(\mathrm{P})$ layer was deposited thereon by means of the electroless plating solution defined in Table II, the $\mathrm{pH}$ of which was regulated by $3 \mathrm{M}$ $\mathrm{NaOH}$. In this experiment, plating conditions were as follows: $\mathrm{pH}$ value $=7.8 \pm 0.3$, temperature $=75 \pm$ $2^{\circ} \mathrm{C}$, V/A $\left(\mathrm{mL} / \mathrm{cm}^{2}\right) \geq 20$, and plating time was adjustable with respect to the required thickness. A surface profiler (KLA-TENCOR P-10, California) measured the thickness of the $\operatorname{Co}(\mathrm{P})$ layer on substrates subjected to different plating times, and the plating rate was obtained. After the specimens were washed by DI water and then blown dry by a nitrogen
Table I. Solution for Roughening, Sensitization, Activation, and Immersion Time

\begin{tabular}{|c|c|c|c|}
\hline Step & Composition & Concentration & $\underset{\text { Time }}{\text { Immersion }}$ \\
\hline Roughening & $\mathrm{H}_{2} \mathrm{SO}_{4}$ & 5 wt. $\%$ & $10 \mathrm{~min}$ \\
\hline Sensitization & $\begin{array}{c}\mathrm{SnCl}_{2} \cdot 2 \mathrm{H}_{2} \mathrm{O} \\
\mathrm{HCL}\end{array}$ & $10 \mathrm{~g} / \mathrm{L}$ & $10 \mathrm{~min}$ \\
\hline Activation & $\underset{\mathrm{HCL}}{\mathrm{PdCl}_{2}}$ & $\begin{array}{l}0.1 \mathrm{~g} / \mathrm{L} \\
8 \mathrm{~mL} / \mathrm{L}\end{array}$ & $45 \mathrm{sec}$ \\
\hline
\end{tabular}

Table II. Compositions of Electroless Plating Bath
Composition

$\mathrm{CoSO}_{4} \cdot 7 \mathrm{H}_{2} \mathrm{O}$

$\mathrm{NaH}_{2} \mathrm{PO}_{2} \cdot \mathrm{H}_{2} \mathrm{O}$

$\mathrm{Na}$ citrate

$\left(\mathrm{NH}_{4}\right)_{2} \mathrm{SO}_{4}$
Concentration $(g / L)$

35

40

35

70 jet, a $\mathrm{Cu}$ wetting layer of $800 \mathrm{~nm}$ and eutectic $\mathrm{PbSn}$ solder layer were sequentially deposited thereon. The $\mathrm{PbSn} / \mathrm{Cu} / \mathrm{Co}(\mathrm{P}) / \mathrm{Cu} / \mathrm{Ti} / \mathrm{Si}$ specimens were then annealed in a furnace at $250^{\circ} \mathrm{C}$ in an ambient of forming gas $(5 \%$ $\mathrm{H}_{2} / 95 \% \mathrm{~N}_{2}$ ) for $0,0.5,6,18$, and $24 \mathrm{~h}$, respectively. The procedure for specimen preparation is summarized in Fig. 1.

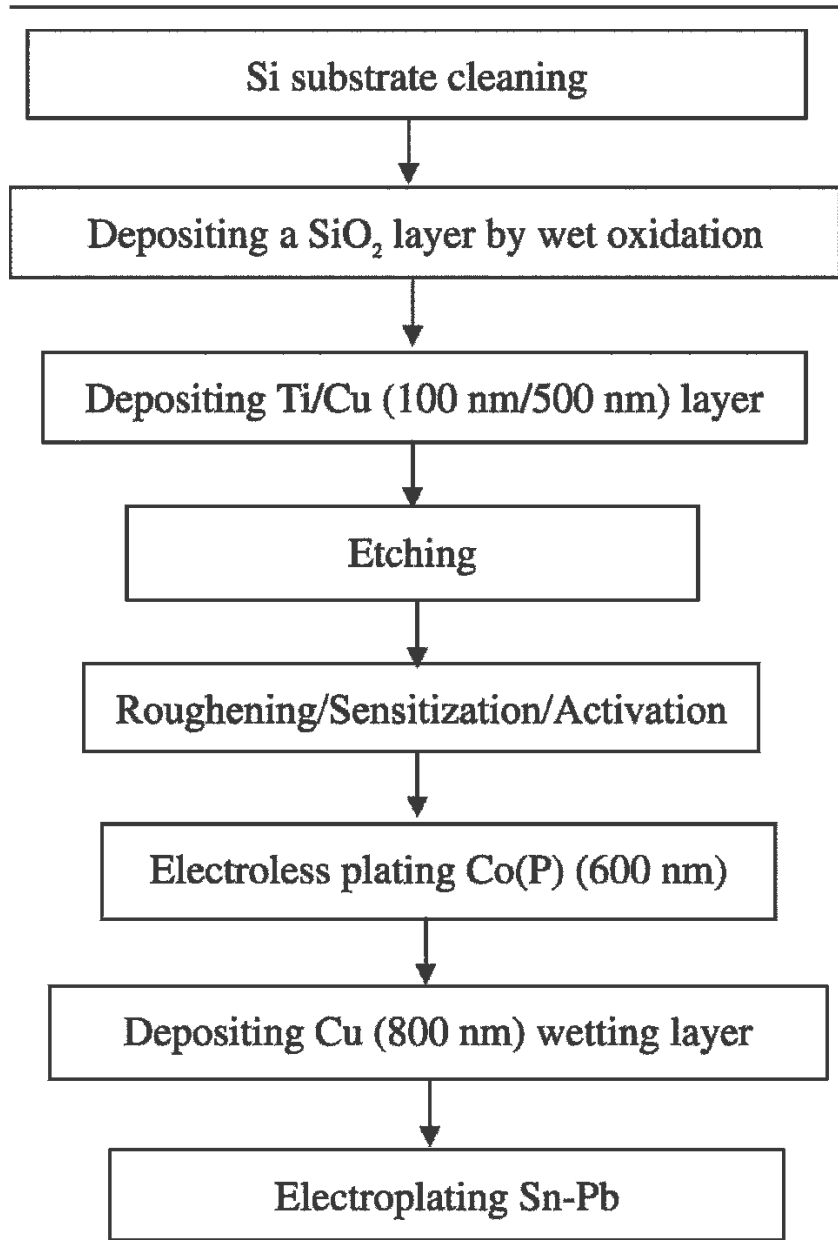

Fig. 1. Flowchart of specimen preparation. 


\section{Structure, Morphology, and Composition Characterization}

The crystal structures of electroless $\mathrm{Co}(\mathrm{P})$ films were characterized by x-ray diffractometry (M18 $\mathrm{XHF}, \mathrm{MacScience)}$. The $\mathrm{x}$-ray source was $\mathrm{Cu} \mathrm{\textrm {K } _ { \alpha }}$ radiation of wavelength $0.154 \mathrm{~nm}$, operated at $200 \mathrm{~mA}$ and $50 \mathrm{kV}$, with a scan rate of $4 \% \mathrm{~min}$.

Scanning electron microscopy (SEM, FE-SEM JSM-6500F or FE-SEM Hitachi S-4700) was used to examine the morphology and cross-sectional structures of each specimen. Composition analysis was performed using Auger electron spectroscopy (AES, VG350) and energy dispersive spectrometry (EDX, Oxford Inca Energy 300) attached to the SEM. In addition, the EDX line scan was adopted to analyze the composition change for cross-sectional specimens subjected to different durations of thermal treatment. The line scan started from the $\mathrm{Cu}$ layer of the substrate and continued toward the $\mathrm{PbSn}$ solder, adopting at least four points of each specimen for analysis so as to obtain the averages thereof for further discussion.

\section{RESULTS AND DISCUSSION}

\section{Deposition Rate of Electroless Co(P) Layer}

Figure 2 is a profile showing plating time vs. thickness of electroless $\mathrm{Co}(\mathrm{P})$. At the beginning of the plating process, the deposition rate was faster because the concentration of the plating bath is higher; the thickness could reach $100 \mathrm{~nm}$ in the first $30 \mathrm{~s}$, while the average plating rate is $130 \mathrm{~nm} / \mathrm{min}$. The chemical reaction formula of electroless plating $\mathrm{Co}(\mathrm{P})$ indicates that the deposition rate increase with the increase of $\mathrm{pH}$ value because an alkaline environment is preferred for electron release. ${ }^{10}$ Table III shows average thicknesses of plated layers under conditions of different $\mathrm{pH}$ values at $75^{\circ} \mathrm{C}$. Note that the thickness of the plated layer increases

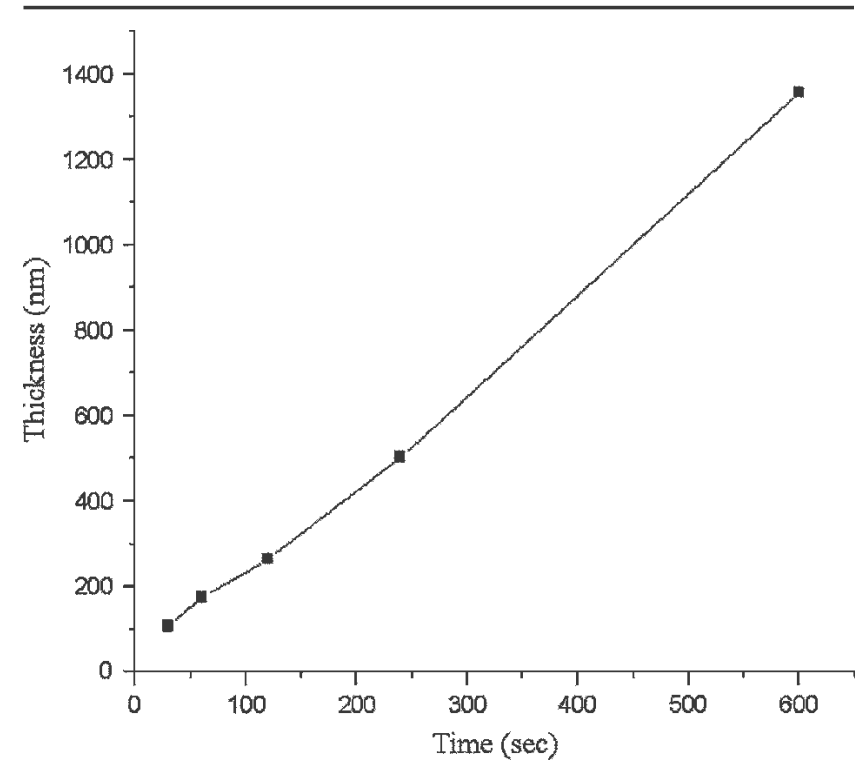

Fig. 2. Thickness of electroless plating $\mathrm{Co}(\mathrm{P})$ layer vs. deposition time.
Table III. Average Thickness of Plated Co(P) Layer

\begin{tabular}{lc}
\hline pH value & $\begin{array}{c}\text { Average Thickness } \\
\text { for 30 sec (nm) }\end{array}$ \\
$\begin{array}{lc}\text { for } \\
8.0\end{array}$ & 100 \\
8.5 & 160 \\
\hline
\end{tabular}

as the $\mathrm{pH}$ value increases, which reveals that the alkaline environment is beneficial for increasing the deposition rate. In addition, chemical reactions can be enhanced by increasing the temperature, such that the higher the temperature, the faster the deposition rate.

\section{Morphologies of Electroless $\operatorname{Co}(\mathbf{P})$ Layer}

The number and size of palladium (Pd) granules formed on the sample were affected by the time that the sample was immersed in the activation solution. If the activation time was too short, the Pd granules were insufficient to cover the sample completely. If the activation time was too long, the size of each $\mathrm{Pd}$ grain might exceed $100 \mathrm{~nm}$ and too many Pd precipitates could be formed and left in the plating bath. It was found that an experimental activation time of $\sim 45$ sec could produce Pd granules of size 20-30 nm uniformly covering the substrate surface.

In addition to the phosphorous content of the plated layer, variation of $\mathrm{pH}$ values also affects the clustering of $\mathrm{Co}(\mathrm{P})$ nucleation. Figure 3 shows the morphologies of $\mathrm{Co}(\mathrm{P})$ layers deposited on the polished $\mathrm{Cu}$ plate after immersion in plating baths of different $\mathrm{pH}$ values for $60 \mathrm{sec}$ each. Noted that the size of $\mathrm{Co}(\mathrm{P})$ clusters increases as the $\mathrm{pH}$ increases, whereas surface coverage is best at $\mathrm{pH}=8.5$. The structure of $\mathrm{Co}(\mathrm{P})$ clusters changes into conifer-leaf shape at $\mathrm{pH}=9.0$. Because the $\mathrm{Co}(\mathrm{P})$ layer was formed by replacing the activated $\mathrm{Pd}$ atoms, the density and the continuity of the electroless $\mathrm{Co}(\mathrm{P})$ layer were affected by the cluster condition of $\mathrm{Pd}$ atoms and the condition of the substrate surface. As revealed by subsequent SEM and XRD analyses, the many particles formed on the specimen surface were not caused by the crystallization during electroless plating, but rather by clustering effects. Clusters grew as deposition time increased, and eventually the clusters became large particles.

\section{Composition Analysis of Electroless Co(P) Layer}

It is known that the amount of phosphorous content in $\mathrm{Co}(\mathrm{P})$ film affects the structure and surface morphology of the plated films. When the phosphorous content in $\mathrm{Co}(\mathrm{P})$ film is within the range of 8 10 at.\%, the formed crystal grain is nanocrystalline. When the phosphorous content in $\mathrm{Co}(\mathrm{P})$ film is within the range of $10-12$ at.\%, the electroless $\mathrm{Co}(\mathrm{P})$ layers are mixtures of amorphous and nanocrystalline structures. When the phosphorous content in $\mathrm{Co}(\mathrm{P})$ 

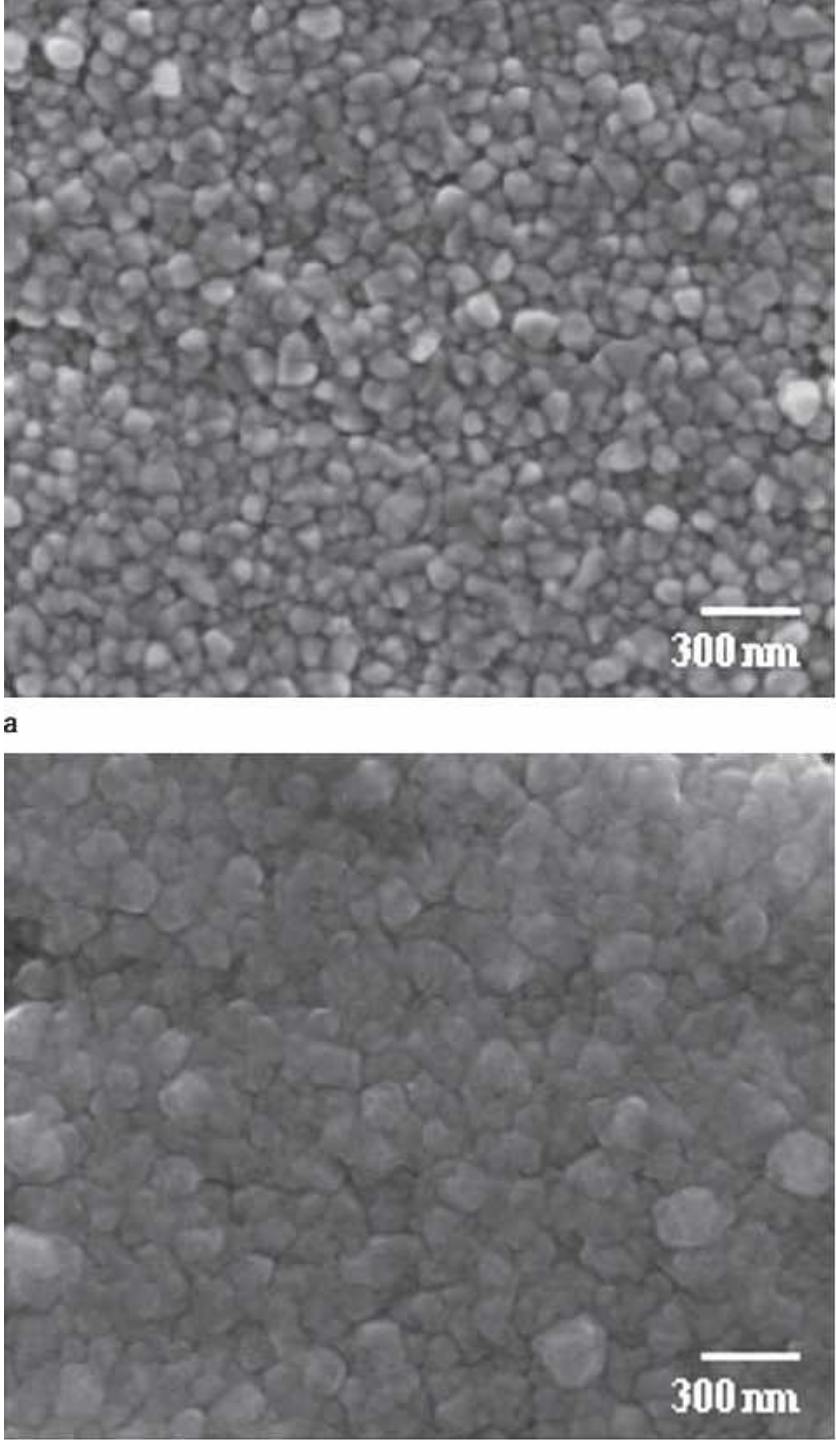

C

Fig. 3. Surface morphologies of Co layers deposited at different pH values: (a) 7.5; (b) 8.0; (c) 8.5; (d) 9.0.

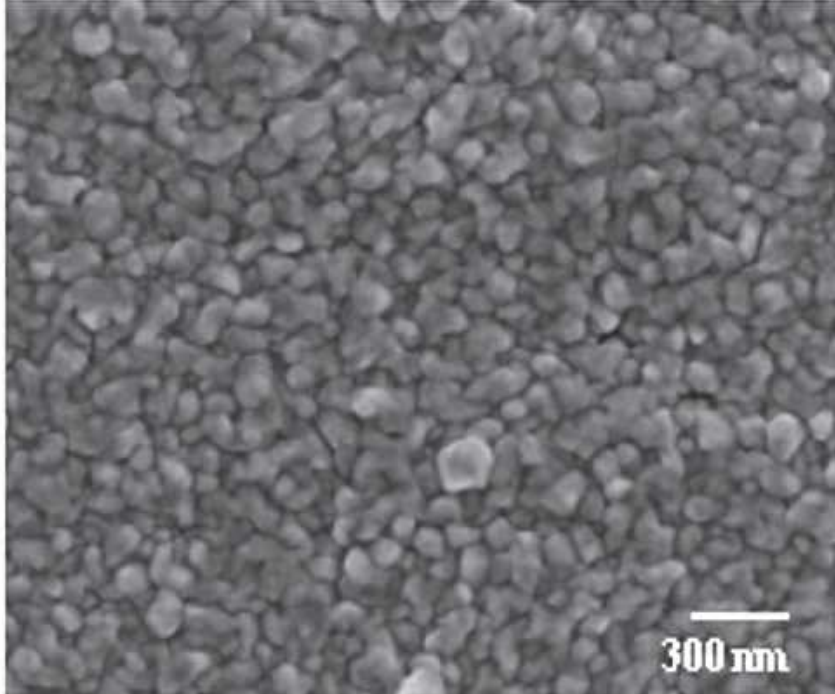

b

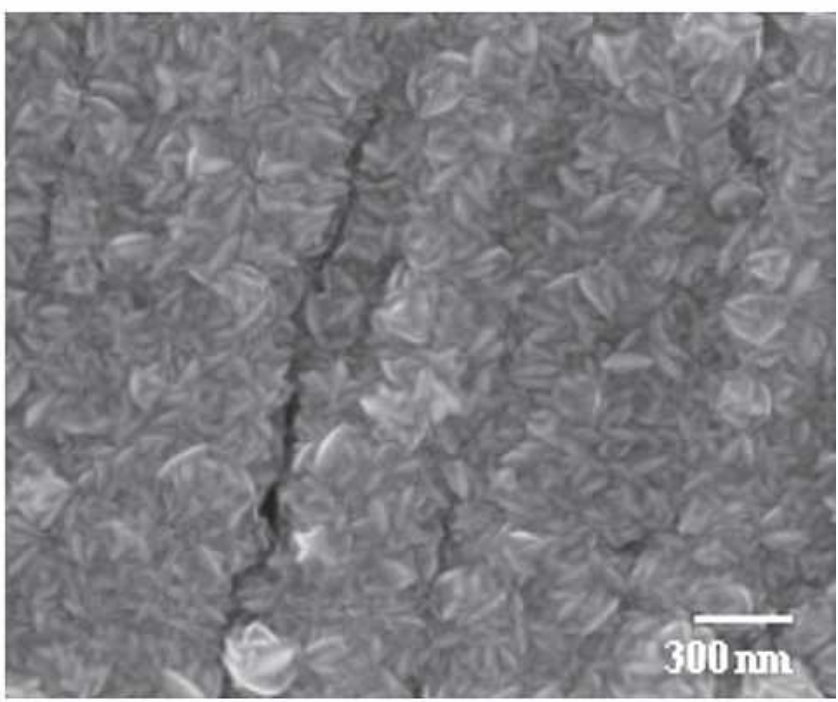

film exceeds 12 at.\%, the electroless $\mathrm{Co}(\mathrm{P})$ layers have an amorphous structure. ${ }^{16}$ The amorphous structure starts to crystallize into $\alpha$-Co at $\sim 290^{\circ} \mathrm{C}$, and orthorhombic crystals of $\mathrm{Co}_{2} \mathrm{P}$ appear at $420^{\circ} \mathrm{C} .{ }^{15}$ Thermal treatment of the present experiment occurred at $250^{\circ} \mathrm{C}$, so that the two types of Co crystals would not appear in the same experiment. According to composition analysis of the $\mathrm{Co}(\mathrm{P})$ thin film, the phosphorous content in the $\mathrm{Co}(\mathrm{P})$ film varied with changes in the deposition time. As seen in Table IV, the phosphorous content in the $\mathrm{Co}(\mathrm{P})$ film decreases as deposition time increases, but the minimum amount is still $>8.7$ at. $\%$ at any deposition time. Therefore, specimens of this experiment had nanocrystalline and amorphous structures, which was proven by subsequent XRD analysis.

Figure 4 shows an AES analysis depicting the depth profile of a $600-\mathrm{nm}$ electroless $\mathrm{Co}(\mathrm{P})$ layer with 5-min. deposition time. The horizontal axis represents the depth of the $\operatorname{Co}(\mathrm{P})$ layer from the surface down, and the vertical axis represents the average phosphorous content of a $100-\mathrm{nm}$ thick $\mathrm{Co}(\mathrm{P})$ film. As seen in Fig. 4, the phosphorous content increases with the depth of the $\mathrm{Co}(\mathrm{P})$ layer, and, at the interface between the $\operatorname{Co}(\mathrm{P})$ and the $\mathrm{Ti} / \mathrm{Cu}$ layers, the phosphorous content reaches its maximum, i.e., $\sim 18$ at.\%. To sum up, the phosphorous content is the highest at the beginning of the

Table IV. EDX Phosphorous Contents with Respect to Different Deposition Times

\begin{tabular}{lcc}
\hline $\begin{array}{l}\text { Deposition } \\
\text { Time (sec) }\end{array}$ & Co (at.\%) & P (at.\%) \\
30 & 85.0 & 15.0 \\
60 & 86.0 & 14.0 \\
120 & 86.7 & 13.3 \\
240 & 89.7 & 10.3 \\
600 & 91.3 & 8.7 \\
\hline
\end{tabular}




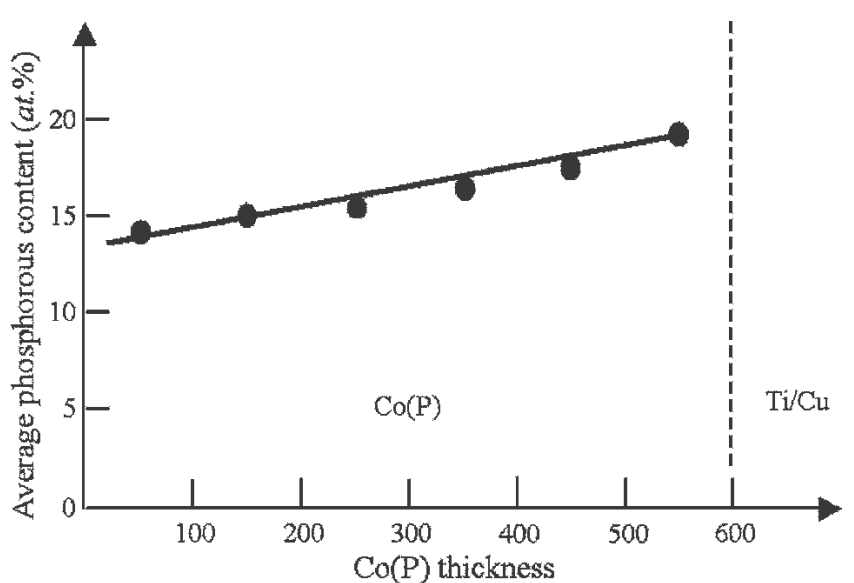

Fig. 4. Average phosphorous content of electroless $\mathrm{Co}(\mathrm{P})$ analyzed by AES.

electroless plating and decreases gradually as deposition time progresses. It was speculated that, with the increase of deposition time, the electroless $\mathrm{Co}(\mathrm{P})$ structure is in transition from amorphous to nanocrystalline or even polycrystalline structure.

\section{XRD Analysis of the Plated Layer}

As seen in Fig. 5, the 30 -sec $\mathrm{Co}(\mathrm{P})$ layer has no obvious Co peak, but it does have has only two $\mathrm{Cu}$ (111) and (200) peaks; therefore, in conjunction with previous AES analysis, it can be concluded that, at the early stages of plating, the electroless $\mathrm{Co}(\mathrm{P})$ layer formed is amorphous. With increasing deposition time, the height of Co peaks increases while that of the $\mathrm{Cu}$ peaks decreases relatively. For a

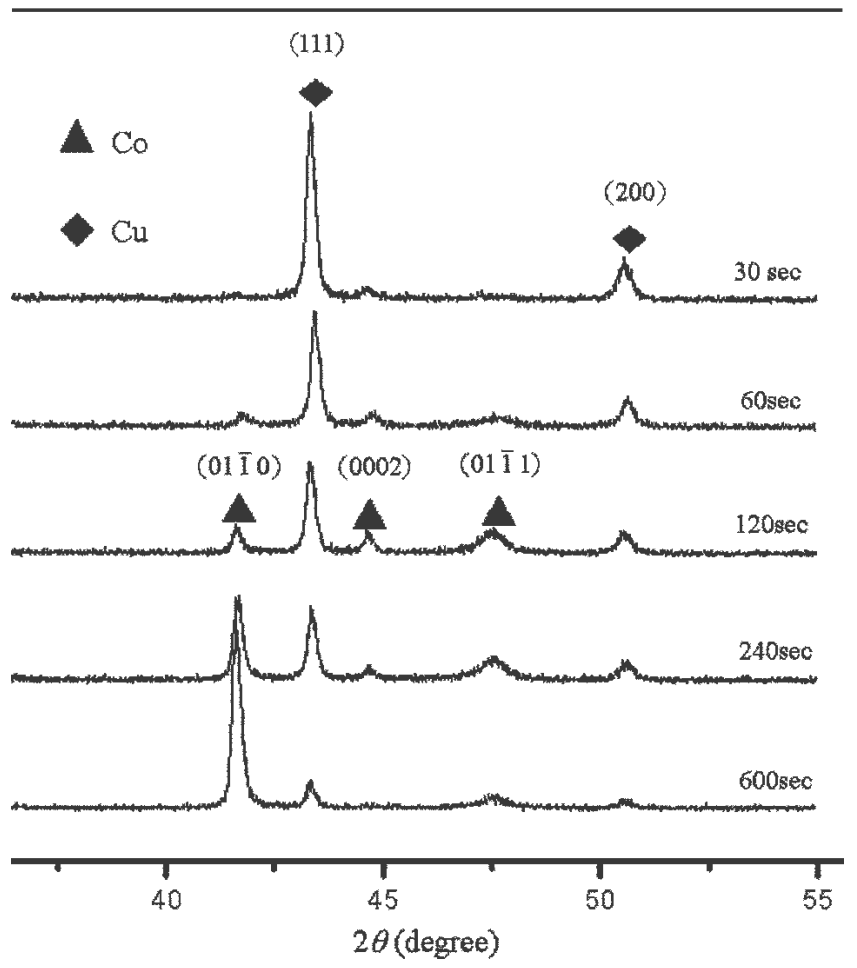

Fig. 5. XRD analysis performed on $\mathrm{Co}(\mathrm{P})$ films with different deposition times. specimen being plated for $600 \mathrm{sec}$, the peak corresponding to (0110) is significant compared to those corresponding to (0002) and (0111). Therefore, the nanocrystalline structure grows as the phosphorus content decreases. With an increase in deposition time, the nanocrystalline area was gradually amplified, and thereby significant Co peaks were observed in the XRD pattern. Figure 6 shows the XRD pattern of $\mathrm{Co}(\mathrm{P})$ films deposited for $30 \mathrm{~min}$., whose thickness is $\sim 2.5 \mu \mathrm{m}$. As seen in Fig. 6 , the pronounced Co peaks corresponding to (0110), (0002), and $(01 \overline{1} 1)$ reveal that the $30-\mathrm{min}$. $\mathrm{Co}(\mathrm{P})$ film has a polycrystalline structure.

The grain sizes in the $\mathrm{Co}(\mathrm{P})$ film can be estimated by using Scherrer's formula ${ }^{17}$ incorporating the XRD peak information:

$$
\mathrm{t}=\frac{0.9 \lambda}{\mathrm{B} \cos \theta},
$$

where $t$ corresponds to the grain size of crystal, $\lambda$ is wavelength of the $\mathrm{x}$-ray $(0.154 \mathrm{~nm}), B$ represents the half-height width of the XRD peak, and $\theta$ represents the Bragg angle. The calculated grain sizes of the $60-\mathrm{s}$ and $30-\mathrm{min}$. Co(P) layers were $\sim 8.42 \mathrm{~nm}$ and $\sim 34 \mathrm{~nm}$, respectively. Moreover, the 600-s $\mathrm{Co}(\mathrm{P})$ layer formed a nanocrystalline structure with a grain size of 20-30 $\mathrm{nm}$. According to the EDX analysis (Table IV), the phosphorous content of the 30 -sec deposition film reaches 15.0 at.\%. The phosphorous content decreases as the deposition time increases, and the structure of the $\mathrm{Co}(\mathrm{P})$ film varied, too. Because the concentration of $\left(\mathrm{HPO}_{2}{ }^{-}\right)$ads was at its maximum at the beginning of the electroless plating, the driving force for the reduction was also

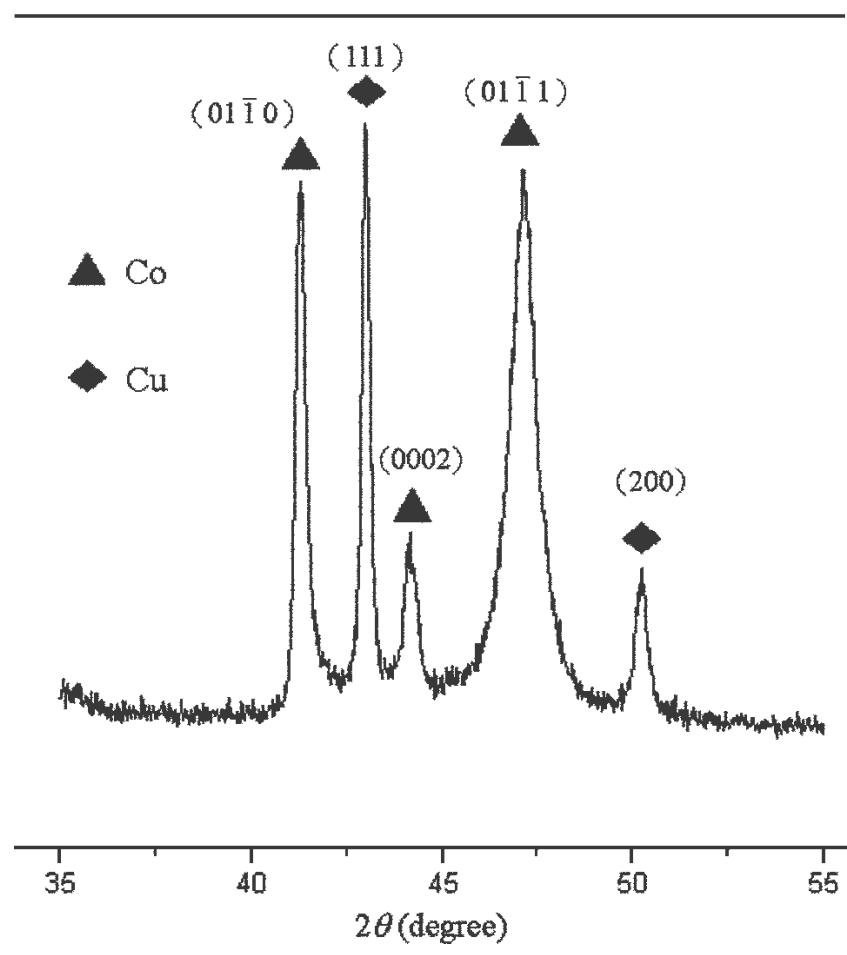

Fig. 6. XRD analysis performed on $\mathrm{Co}(\mathrm{P})$ films with 30-min. deposition time. 
at its maximum and thus the amount of phosphorus being deposited was at its relative maximum. ${ }^{10}$ Because the plating process is a chemical reaction rather than a physical change, the phosphorous content in the plated film changes during the chemical reaction. The fact that the phosphorous content in the plated film decreases with a decrease in the concentration of $\left(\mathrm{HPO}_{2}{ }^{-}\right)$ads hence causes the microstructural changes in the electroless plating film. It can thus be speculated that a $\mathrm{Co}(\mathrm{P})$ layer of amorphous structure formed at the beginning of the plating process can retard the diffusion of $\mathrm{Sn}$ and $\mathrm{Cu}$ atoms.

\section{Interfacial Reactions of Electroless $\operatorname{Co}(\mathbf{P})$ Layer and Pb-Sn Solder}

Because the specimens were treated at $250^{\circ} \mathrm{C}$, which is higher than the eutectic temperature of $\mathrm{Pb}-\mathrm{Sn}$ solder, the interfacial diffusion of present experiment progressed in the liquid state. The $\mathrm{Cu}$ wetting layer reacted with the $\mathrm{Pb}-\mathrm{Sn}$ solder first, and the intermetallic compounds (IMCs) were produced. The IMCs produced under different durations of thermal treatment were subjected to EDX analysis, and the results are shown in Table V. Noted that the ratio of $\mathrm{Cu}$ and $\mathrm{Sn}$ falls in the range of 1.5-2.0, such that the IMCs could be a mixture of $\mathrm{Cu}_{6} \mathrm{Sn}_{5}$ and $\mathrm{Cu}_{3} \mathrm{Sn}$. This emergence of a $\mathrm{Cu}_{3} \mathrm{Sn}$ phase could result from prolonged thermal treatment at a temperature relatively higher than the eutectic temperature of the $\mathrm{Pb}-\mathrm{Sn}$ solder.

Figures $7 \mathrm{a}$ and $\mathrm{b}$ present the cross-sectional SEM micrographs and results of EDX line scan for the 6- and 24-h annealed specimens, respectively. In either case, the peak representing $\mathrm{Sn}$ abruptly decays when it reaches the $\mathrm{Co}(\mathrm{P})$ layer. This evidences that Sn could not penetrate the
Table V. EDX Analysis of IMCs Produced under Different Durations of Thermal Treatment

\begin{tabular}{lc}
\hline Thermal & \\
Duration (h) & Ratio $(\mathbf{C u} / \mathbf{S n})$ \\
0.5 & 2 \\
6 & 1.65 \\
18 & 1.73 \\
24 & 1.56 \\
\hline
\end{tabular}

$\mathrm{Co}(\mathrm{P})$ layer after such a liquid-state annealing, and hence the $\mathrm{Co}(\mathrm{P})$ layer clearly serves as a good diffusion barrier for UBM structures. In the foregoing XRD analysis, it was speculated that the first-formed $\mathrm{Co}(\mathrm{P})$ layer is high in phosphorous content and thus should be amorphous. The fact that $\mathrm{Sn}$ could not penetrate the $\mathrm{Co}(\mathrm{P})$ layer revealed in the EDX line scan analysis further proves the speculation. Moreover, it is noted that peaks representing $\mathrm{Co}$ and $\mathrm{Cu}$ underlayers are separated without overlapping. Hence, $\mathrm{Cu}$ could not penetrate a $\mathrm{Co}(\mathrm{P})$ layer, either. Thus, the electroless $\mathrm{Co}(\mathrm{P})$ layer can serve as a good diffusion barrier of UBM structure for both $\mathrm{Cu}$ interconnects and solder bumping of flip-chip Cu-ICs.

\section{CONCLUSIONS}

This work studies the electroless plating of a $\mathrm{Co}(\mathrm{P})$ layer and its feasibility in UBM structures. At the beginning of the plating process, the deposition rate of $\mathrm{Co}(\mathrm{P})$ layer was at its fastest because the concentration of the plating bath was relatively high. The chemical reactions of electroless plating $\mathrm{Co}(\mathrm{P})$ indicated that the deposition rate increased with increasing $\mathrm{pH}$ values. AES and EDX analyses indicated that the phosphorous contents in $\mathrm{Co}(\mathrm{P})$
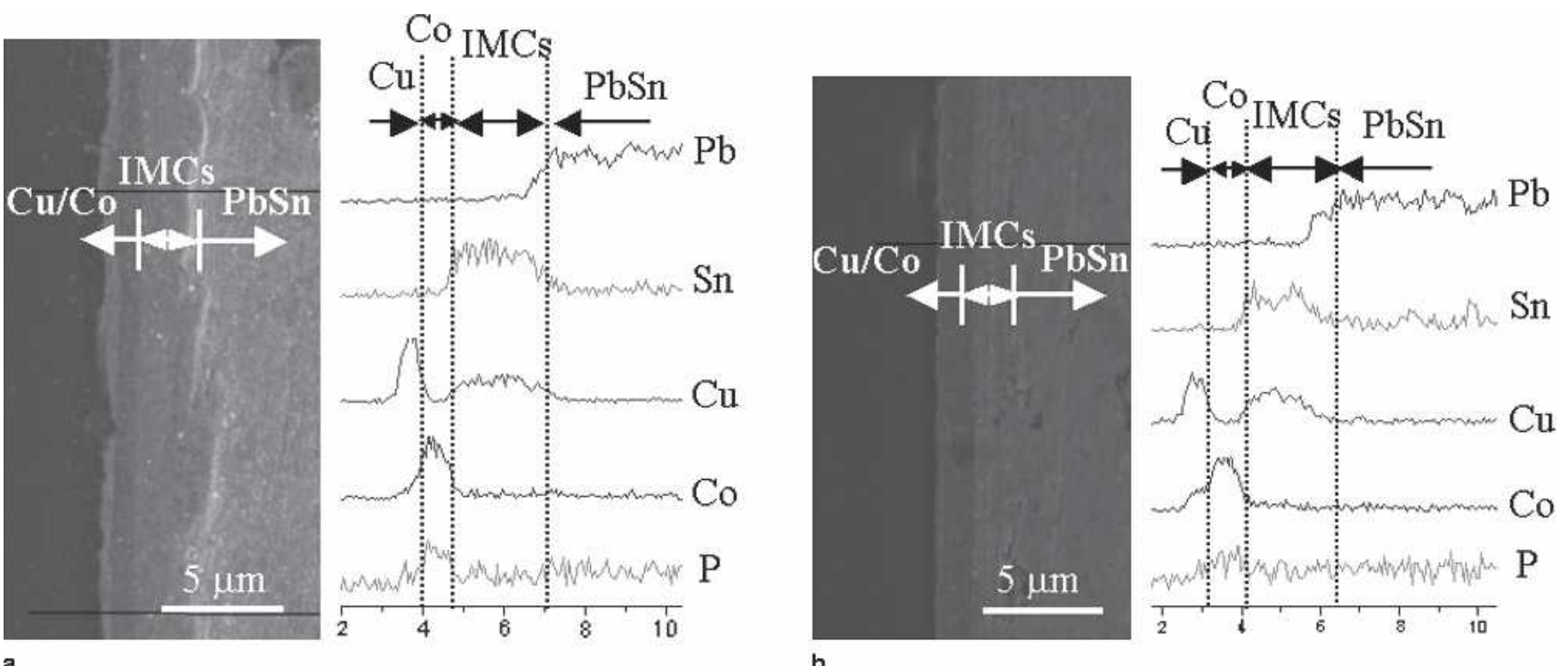

Fig. 7. Cross-sectional SEM view of specimen interfaces and corresponding line-scanning EDX analyses after annealing at $250^{\circ} \mathrm{C}$ for (a) $6 \mathrm{~h}$ and (b) $24 \mathrm{~h}$. 
films decreased with increases of film thickness and that average contents are no less than 8.7 at.\% for the specimens. Although XRD in conjunction with composition analyses revealed that the electroless $\mathrm{Co}(\mathrm{P})$ layer prepared in this work was a mixture of amorphous and nanocrystalline structures, the AES depth profile analysis revealed that the phosphorous content in $\mathrm{Co}(\mathrm{P})$ film formed at the beginning of the plating process could reach a concentration as high as 18 at.\%. This implied that the first-formed electroless $\mathrm{Co}(\mathrm{P})$ layer is amorphous, and that it would possess a good ability to retard diffusion. As revealed by the EDX line-scan analysis, neither Sn nor $\mathrm{Cu}$ underlayers could penetrate the electroless $\mathrm{Co}(\mathrm{P})$ layer in the $\mathrm{PbSn} / \mathrm{Cu} / \mathrm{Co}(\mathrm{P}) / \mathrm{Cu} / \mathrm{Ti} / \mathrm{Si}$ sample subjected to annealing at $250^{\circ} \mathrm{C}$ in a forming gas ambient for $24 \mathrm{~h}$. The EDX analysis also indicated that, in addition to the formation of $\mathrm{Cu}_{6} \mathrm{Sn}_{5}$ and $\mathrm{Cu}_{3} \mathrm{Sn}$ phases, diffusion of Co atoms into the solder region was negligible, and no metallurgical reaction could be observed. Hence the electroless $\mathrm{Co}(\mathrm{P})$ layer may simultaneously serve as a diffusion barrier of $\mathrm{Cu}$ interconnects and as an UBM structure in flipchip Cu-ICs.

\section{ACKNOWLEDGEMENTS}

This work was supported by the Department of Industrial Technology, Ministry of Economics Affairs of the ROC under TDPA (Technology Development Program for Academia, Contract No. 92-EC17-A-05-S1-020), and the National Science Council of the R.O.C. (Contract No. NSC93-2216-E-009-008).

\section{REFERENCES}

1. T.T. Kodas and M.J. Hampden-Smith, ed., The Chemistry of Metal CVD (New York: VCH, 1994), p. 9.

2. C.-Y. Lee, T.-H. Huang, and S.-C. Lu, J. Mater. Sci. 9, 337 (1998).

3. M. Paunovic, P.J. Bailey, and R.G. Schad, J. Electrochem. Soc. 141, 337 (1994).

4. J.H. Lau, Flip Chip Technologies (New York: McGraw-Hill, 1996).

5. T. Oppert, E. Zakel, and T. Teutsch, Proc. IEMT/IMC Symp. Tokyo, Japan (Piscataway, NJ: IEEE, 1998), p. 106.

6. T. Teutsch, T. Oppert, E. Zakel, and E. Klusmann, Electronic Components and Technology Conference (ECTC), Las Vegas, NV (Piscataway, NJ: IEEE, 2000), p. 107.

7. G.O. Mallory and J.B. Hajdu, Electroless Plating Fundamentals and Applications (Orlando, FL: AESF, 1990), Chap. 1-7.

8. R.H. Uang, K.C. Chen, S.W. Lu, H.T. Hu, and S.H. Huang, IEEE Electron. Packag. Technol. Conf. Singapore (Piscataway, NJ: IEEE, 2000), p. 292.

9. G.G. Gawrilov, Chemical (Electroless) Nickel-Plating (Redhill: Portcullis Press, 1974), Chap. 5.

10. E.J. O'Sullivan, A.G. Schrott, M. Paunovic, C.J. Sambucetti, J.R. Marino, P.J. Bailey, S. Kaja, and K.W. Semkow, IBM J. Res. Dev. 42, 607 (1998).

11. B. Thaddeus, X. Massalski, J.L. Murray, L.H. Bennett, and H. Baker, Binary Alloy Phase Diagrams (Metals Park, OH: American Society for Metals, 1986).

12. R. Labie, E. Beyne, and P. Ratchev, Electronic Components and Technology Conference (ETCT), (Piscataway, NJ: IEEE, 2003), p. 1230.

13. R. Labie, E. Beyne, R. Mertens, P. Ratchev, and J. Van Humbeeck, IEEE Electron. Packag. Technol. Conf. Singapore (Piscataway, NJ: IEEE, 2003), p. 584.

14. A. Kohn, M. Eizenberg, and Y. Shacham-Diamand, J. Appl. Phys. 92, 5508 (2002).

15. A. Kohn, M. Eizenberg, and Y. Shacham-Diamand, Appl. Surf. Sci. 212, 367 (2003).

16. L.A. Chekanova, E.A. Denisova, and R.S. Iskhakov, IEEE Trans. Magn. 33, 3730 (1997).

17. B.D. Cullity and S.R. Stock, Elements of X-Ray Diffraction, 3rd ed. (New Jersey: Prentice Hall, 2001). 